Open Access

\title{
Empirical study on relationship between corporate social responsibility and financial performance in Korea
}

\author{
Jae-Joon Han ${ }^{1}$, Hyun Jeong $\mathrm{Kim}^{2^{*}}$ (D) and Jeongmin $\mathrm{Yu}^{1}$
}

\footnotetext{
* Correspondence: kimhj@inha.ac.kr ${ }^{2}$ College of Business Administration, Inha University, 100 Inha-Ro, Nam-Gu, Incheon 22212, Korea Full list of author information is available at the end of the article
}

\begin{abstract}
There have been numerous studies on corporate social responsibility (CSR) and its relation to corporate performance. Recently, studies in this field have paid particular attention to the method of measurement in order to identify the CSR activities. One of the widely recognized measures to proxy CSR is the Environmental, Social, and Governance (ESG) score. This paper examines the relationship between Corporate Social Responsibility (CSR) and corporate profit by testing the ESG performance score on the firm's Financial Performance (FP), specifically for Korea Stock Market (KOSPI) listed firms in the period of $2008 \sim 2014$. We use three separate individual Environmental, Social and Corporate Governance (ESG) disclosure scores from Bloomberg for the CRS proxy measure, as well as the Return on Equity (ROE), Market-to-Book Ratio (MBR) and Stock Return for the FP measures. We found that the ESG disclosure scores (the measures of environmental, social, and governance responsibility performance) in the Korean corporations shows diversified results. Particularly, the environmental responsibility performance score presents a negative (or $U$ curve) relationship with FP, whereas the governance responsibility performance score presents a positive (or inverse $U$ curve) relationship with FP. On the other hand, we did not find any statistically significant evidence of a relationship between the social responsibility performance score and FP.
\end{abstract}

Keywords: Corporate social responsibility (CSR), Environmental, Social, Governance (ESG), Financial performance (FP), Sustainability

\section{Introduction}

Corporate Social Responsibility (CSR) is a form of corporate self-regulation integrated into business models. CSR functions as a self-regulatory mechanism by which a corporation ensures its active compliance with the spirit of the law and ethical standards. Its aim is to increase the long-term profits or survival of a firm through constructing positive public relations and high ethical standards, in order to reduce the business and legal risk and build shareholder trust. Accordingly, the CSR strategies of a corporation are tightly related to its sustainable growth. To ensure sustainable growth, it is necessary for a company to make a positive impact on the surrounding environment, as well as on its stakeholders, such as its consumers, employees, investors, communities, and others. Beltratti (2005) and Jamali et al. (2008) examined the positive relationship among CSR, corporate governance, and the enhancement of the firm's value. Furthermore, Beltratti (2005) concluded that by ensuring the protection of the stakeholders, firms are more likely to survive in the long term, and

(c) The Author(s). 2016 Open Access This article is distributed under the terms of the Creative Commons Attribution 4.0 International License (http://creativecommons.org/licenses/by/4.0/), which permits unrestricted use, distribution, and reproduction in any medium, provided you give appropriate credit to the original author(s) and the source, provide a link to the Creative Commons license, and indicate if changes were made. 
Aras and Crowther (2008) pointed out the significance of the corporate governance and the subsequent sustainability of firm.

Thus, CSR has become a noticeable issue in the management literature, not only from a theoretical point of view, but also from empirical methods' point of view about how to measure CSR activities (McWilliams et al. 2006; Dobers 2009; Nejati and Ghasemi 2012). Attempts to identify the relationship between CSR and the performance of firms have been made by many scholars (Aupperle et al. 1985; Mittal et al. 2008; Crisóstomo et al. 2011).

Possible explanations for the lack of consensus and difficulties in measuring CSR have been given in previous studies (Waddock and Graves 1997). One possibility is to attribute this inconsistency to the multidimensional CSR concept and its interrelationship across many disciplines; varying concepts and issues from strategic perspectives to human resource management, culture, and stakeholder/shareholder ones. Another research group suggested that these unidentified and omitted explanatory variables (McWilliams and Siegel 2000) made it difficult understand the latent mechanisms. Meanwhile, several studies tested the existence of a relationship between a firm's CSR performance and FP. However, these findings are rather inconclusive in answering the question as to whether a firm's performance in terms of its corporate social responsibility can be translated into positive corporate financial performance (FP). While such a relation (Margolis et al. 2009) sounds appealing, this finding is still fragile, since a range of other studies have reported either negative (Mittal et al. 2008) or mixed results (Schreck 2011). Most of those studies relied heavily on the dataset provided by Kinder, Lydenberg and Domini (KLD). Due to this shortfall, Margolis et al. suggested the need to consider alternative measures of CSR performance. Furthermore, those studies based on the KLD dataset only test for a linear relationship between a firm's CSR and its FP. However, recent developments in microeconomic theory suggested that a non-linear set-up should be considered (Manasakis et al. 2013, 2014; García-Gallego and Georgantzis 2009). A non-linear relationship between CSR and FP is therefore in line with economic intuition, but has rarely been tested, as pointed out in Barnett and Salomon (2012). For instance, those firms which voluntarily engage in more socially responsible activities incur higher corresponding costs at an earlier stage and, therefore, the increase in their CSR score has a negative relationship with their FP if the study is done only linearly. In this line of consideration, Nollet et al. (2016) tested both linear and non-linear relationships between CSR performance and FP. They also used an alternative third-party auditors' data set, viz. Bloomberg's ESG (Environmental, Social, and Governance) disclosure score, as a new proxy for CSR.

At this point, we would like to remark that our research is motivated by both Barnett and Salomon (2012) and Nollet et al. (2016). For the test subject, unlike in the study of Nollet et al. (2016), we chose Korea corporates and their CSR performance for two reasons. Firstly, most of the CSR studies done so far have focused on Western countries, such as the U.S. and Europe, rather than Asian ones, and we wanted to fill this geographical gap. Particularly, Chambers et al. (2003) reported that although there are increasing expectations of socially responsible business in Korea, little research on this topic has actually been done. Secondly, although the domestic literature in Korea includes various studies on CSR, their focus has been on the cultural orientation (e.g. Park et al. 2008; Kim and Kim 2010), ownership structure (Oh et al. 2011), financial 
reporting quality, and corporate governance (Choi and Pae 2011), which have no linkage with FP. Therefore, going one step further, our study also aimed to fill this gap by identifying the relationship between a firm's CSR performance and its profit.

Our study is different from that of Nollet et al. (2016) from three viewpoints, which is our benchmark. Firstly, as mentioned above, this paper considers Korean corporations. To the best of our knowledge, our study is the first to test the relationship between ESG disclosure scores and FP for Korean firms at home and abroad. For our study, the dataset of 94 Korean firms (out of all 700 KOSPI listed firms) that have Bloomberg Environmental Social Governance (ESG) Disclosure scores for the period of 2008-2014 was used.

Secondly, this study examines the effects of CSR (specifically separate ESG scores) on FP by advanced methods, viz. the panel methods (random and fixed effect) and quasimaximum likelihood methods. On the other hand, Nollet et al. (2016) tested the relationship only by the pooled OLS method. We examine the individual ESG disclosure score, i.e. the environmental, social and governance, instead of the overall ESG composite score. Note that Nollet et al. (2016) used the same method. This paper investigates which dimension out of 3 different Environmental Social Governance responsibilities has more effect on FP and how this effect is brought about. We try to answer the following questions. Is there any relationship between individual ESG and FP? If so, is it positive or negative? Furthermore, if the relationship a mixed or inclusive one, what would be the alternative solution? For these reasons, we examine non-linear relationship.

Thirdly, our finding is interesting in the sense that it is basically in line with the study of Nollet et al. (2016), but our finding shows a different pattern. We confirmed the existence of a non-linear relationship in Korean corporations, similar to that shown by Nollet et al. (2016) in US corporations. However, our non-linear relationship pattern is different from theirs. For reference, Nollet et al (2016) found both a linearly negative and non-linearly $U$ curve relationship only between GDS (Governance Disclosure Score, proxy for CSR effort in Governance dimension) and FP in US corporations. By contrast, we observed that the same relationship exists for Korean firm between EDS (Environmental Disclosure Score, proxy for CSR effort in Environmental dimension) and FP, but not between GDS and FP. For GDS, we found the opposite pattern (i.e., a linearly positive and non-linearly inverse $U$ curve relationship) compared to what Nollet et al (2016) found. On the other hand, we did not find any empirical evidence on the relationship between SDS (Social Disclosure Score) and FP. This is the same finding as that of Nollet et al. (2016) in SDS for US firms.

\section{Literature review and ESG overview}

\section{CSR and FP}

From the earliest classic studies by Bowen (1953), Eells and Walton (1961), McGuire (1963), Carroll (1979), the importance of CSR and its impact on society has been explored from various viewpoints. However, their opinions are divided on the need for corporate CRS. Some studies with a positive appraisal of CSR argued that 'a corporation has a duty to society' (Andrews 1973; Davis and Blomstrom 1975; Carroll 1979; Drucker 1984; Epstein 1987), whereas others reported that 'a corporation only has the duty to maximize its benefit within the fence of law and minimum ethical restrictions' (Levitt 1958; Friedman 1970). 
Nonetheless, in the 2000s, various studies identified CSR as a source of competitive advantage (e.g. Russo and Fouts 1997; McWilliams and Siegel 2011). Donaldson and Preston (1995) and Porter and Kramer (2006) investigated whether a strategic CSR activity enhances the competitive advantage of the firms. Baron (2008) argued that CSR activities could be a productive investment. He concluded that CSR helps firms to attract consumers who value CSR expenditures but do not mind paying more for the corporate executives or the employees whose personal values are aligned with CSR. Baron (2008) suggested that some investors might value CSR more, even though it could lower financial profit in the short-run, because they are satisfied by owning such a firm that makes socially responsible expenditures. On the other hand, Besley and Ghatak (2007) found that breaking CSR promises will result in lower profits, whereas more responsible firms will earn higher profits due to their reputational premium. In this regard, Benabou and Tirole (2010) raised the question as to whether CSR helps the firm in the long run. Margolis et al. (2007) found that CSR engagement helps firms to gain a competitive advantage. They reported a positive relation between CSR and performance except in two percent of cases. The role of governance in CSR is also important. Several studies found the importance of sustainable development issues, such as stakeholder dialogue and core values, and of embedding these issues into the firm's strategy. The study of Beltratti (2005), as well as that of Jamali et al. (2008), found a positive relationship between CSR and corporate governance. Beltratti (2005) concluded that by ensuring the protection of the stakeholders, firms are more likely to survive in the long term. Jamali et al. (2008) found that CSR and corporate governance strengthen each other. Furthermore, Aras and Crowther (2008) stressed the significance of the corporate governance and the subsequent sustainability of firm.

Meanwhile, empirical analysis has been inconclusive as to whether adopting CSR has a positive or negative effect on a firm's FP. This is because the empirical findings were divided. The first group of literature finds a positive relationship between CSR and FP. The works of Orlitzky et al. (2003), Wu (2006), and Margolis et al. (2007) in management studies found a significant positive relationship between CSR and FP (Peiris and Evans 2010). The study of Barnett and Salomon (2006, 2012) in finance also suggested that firms with a higher CSR index score have better performance compared to those with a lower CSR score. The longitudinal study by Margolis et al. (2009) conducted from 1972 to 2007 also suggests the positive effect of CSR on accounting and marketbased profits.

On the contrary, the second literature group argues that CSR has a negative effect on FP. Fisher-Vanden and Thorburn (2011) suggested the unfavorable effect of CSR. They found the possibility of the market reacting negatively to news of companies joining an environmentally friendly program, for instance, the Environmental Protection Agency's Climate Leaders program, due to the anticipated negative effect on its financial performance.

Lastly, the third group of Brammer and Millington (2008) argued that a positive or negative relationship can occur depending on the level of CSR. They also provided some empirical evidence for the existence of a U shaped relationship between CSR and FP. Although they did not specifically hypothesize a U shaped relationship, they found evidence that the highest and lowest levels of CSR were associated with the highest 
levels of FP based on the firm-level data. However, in their study, CSR was represented by only one variable (i.e. corporate charitable), which is one of its limitations.

In light of the third group, Mittal et al. (2008) provided the rationale for a negative CSR-FP relationship. That is, when the expected relationship between CSR and FP is U shaped, the negative relationship could be observed at an earlier stage of CSR effort because the cost of CSR caused the initial downward slope of the U curve. Supporting the conjecture of Mittal et al. (2008), Nollet et al. (2016) empirically proved the existence of a U curve shaped relationship between corporate governance and FP in US corporations, and this is the first empirical finding of a $U$ curve relationship in the CSR literature up until now.

Summarizing the above literature shows that the literature findings have been mixed until now, and so further research is needed. On this basis, our study examines the relationship between CSR and FP in Korean corporations. In Korea, recently, various studies of CSR have been conducted on cultural orientation, ownership structure and CSR, and on financial reporting quality, corporate governance and CSR. However, none of them analyzed the relationship between CSR and FP. Thus, we attempt to determine the effect of CSR on FP in Korean firms listed on the Korea (KOSPI) stock markets. For the analysis of Corporate Social Responsibility (CSR), the activities dataset of the individual ESG disclosure scores from Bloomberg in the period of 2008 to 2014 was used as its proxy.

\section{Environmental, Social and Governance (ESG) overview}

Most of the analyses of CSR appear in corporate sustainability reports. However, relying on the individual corporate CSR report has intrinsic shortcomings, such as a biased disclosure problem due to the deficiency of the firm's revelation mechanism, viz. revealing only the firm's favorite interpretation of its CSR and its operationalization (Butz and Pictet 2008). Thus, to investigate the relationship between CSR and FP unbiasedly, several studies examined the relationship based on third party ratings of environmental, social and corporate governance.

Practically, the ESG disclosure score is used as one of the major indexes in the identification of CSR effort. It is used to gain an understanding of the overall CSR activities; how corporations develop CSR issues with respect to their objectives and strategies for long-term growth, how they manage risks and other organizational characteristics in terms of general management practices, and so on. Originally, ESG terminology first appeared in the United Nations Principles of Responsible Investment and then in a number of companies' CSR reports (Davis and Stephenson 2006). Although there is no clear understanding of this concept yet, ESG score has been practically used by major business consulting firms. Bassen and Kovacs (2008) argued that ESG score monitoring is important to implant CSR practically, as well as delivering ESG information in order for investors to assess a corporation's risks and opportunities. Particularly, scoring indicators such as the environment activity (environmental scores and environmental factors), social responsibility (number of employees, employee turnover ratio, employee unionized, women in management, women in employees) and governance mechanisms (size of the board, independent directors, board duration, board meetings per year, women on board) is important. 
Meanwhile, because ESG issues are extra-financial attributes, ESG scores could lack the consistency and standardized definitions (Peiris and Evans 2010) necessary for their comparison. Even with quantified data, it is difficult to compare them with the information delivered by peers and across periods. The ESG disclosure scores used in other studies faced the problem, particularly in terms of their objectivity. As a matter of fact, there are companies which are uncooperative in providing the information necessary to assess the impact of their ESG factors on FP (financial performance) or cases where the ESG score provided by the company lacks consistency. In order to resolve these problems or minimize the ESG measurement bias, this study use the ESG scores provided by Bloomberg, which is a third-party data collecting institution that cares very much about its own reputation for accumulating accurate data.

As shown in the literature review, there are no consistent findings on the relationship between overall CSR and FP yet. We suspected that using the combined ESG score might result in mixed findings or non-significant test results. Thus, we consider the effects of the three individual ESG scores on FP separately, instead of the overall ESG score. As a matter of fact, Nollet, Filis, and Mitrokostas (2016) conducted their study in the same way as ours. They tested for the effects of GDS, SDS, and EDS on FP separately.

We describe the individual ESG score in more detail below. Firstly, the Environmental Disclosure performance Score (EDS) is designed to address the business environment and the relationship between business and society. EDS is known to cover the corporation's disclosure policy issues on their $\mathrm{CO}_{2}$ emissions, energy consumption, total waste, energy efficiency policy, and emissions reduction policy. Secondly, the Social Disclosure performance Score (SDS) covers the company's disclosure policy on the number of employees, employee turnover ratio, number of unionized employees, percentage of women in management, percentage of women employees, and so forth. Both of these scores (EDS and SDS) are likely to be affected by the firm's CSR spending. Thirdly, the Governance Disclosure performance Score (GDS) is designed to reflect the corporate governance structure. ${ }^{1}$

Given the above CSR literature and description of ESG, our research questions the following two hypotheses.

Hypothesis 1. There is a linear and positive effect of Corporate Social Responsibility performance (EDS, SDS, GDS) on Corporate Financial Performance.

Hypothesis 2. The effects of the Environment, Social and Governance performances on Corporate Financial Performance are non-linear, viz. it implies that the relationship could be convex ( $U$ curve) or concave (inverse $U$ curve).

\section{Data description and methodology}

Data description

The paper examines the effect of corporate social responsibility (CSR) on corporate Financial Performance (FP) in both a linear and non-linear framework. Particularly, we investigated the Korean (KOSPI) stock market. As measures of CSR, we used Bloomberg's Environmental, Social, Governance (ESG) Disclosure scores: the Environmental Disclosure Score (EDS), Social Disclosure Score (SDS) and Governance Disclosure Score (GDS). ESG measures the listed firm's CSR performance. We only use individual ESG score, technically because the number of firms whose overall ESG scores are available is relatively too small 
compared to that of the firms whose individual ESG scores are provided, and also due to our suspicion of the mixed result based on the overall score. To measure the corporate Financial Performance (FP), we used the Return on Equity (as a measure of the firms' performance from an accounting perspective), Annual Stock Returns (as a measure of their performance from a market perspective) and Market-to-Book ratio (MBR, as a mixed measure of both perspectives). We adopted the Market-to-Book ratio as a proxy for Tobin's q as in Dowell, Hart, and Yeung (2000). Like these authors, we constructed the MBR by dividing the total of the firm's market capitalization value plus book value of long-term debt plus net current liabilities by the book value of total assets.

Our sample consists of the annual data of firms listed on the Korea Stock Exchange (known as KOSPI firms) in the period of 2008-2014 if their ESG score provision is available. This availability issue restricts the number of sample firms to 94 out of around 700 listed firms. All of the data used in our paper are collected from the Bloomberg terminal. Bloomberg's ESG disclosure score is based on publicly available company material. It covers a wide range of data from $\mathrm{CO}_{2}$ emissions, total waste, energy efficiency, and emissions reduction policy to the share of women on the board and the number of board meetings per year. Its scoring scale ranges from 100 to null disclosure with a score of 0 .

One limitation of using Bloomberg's ESG Disclosure score as the proxy of CSR as in Nollet, Filis, and Mitrokostas (2016) is that, although it is not the corporates' direct ESG effort level itself, it is assumed to reflect firms' ESG responsibility improvement effort. Using the three individual ESG disclosure score provides us with the chance to assess how each CSR activity of firm affects FP improvement and which of these three ESG scores is the key driver for improving FP.

Table 1 presents descriptive statistics of the variables used. Table 2 provides the linear correlation among the variables. Table 1 shows that the three ESG scores have differences. Out of the three scores, GDS shows the highest average value, whereas EDS has the lowest mean value. Regarding the standard errors, GDS is the most stable, while EDS is the least. Another observation regarding the three FP measures is that ROE shows the highest volatility in its standard errors, as well as its minimum and maximum values, while Stock Return turns out to be the least volatile. Finally, other control

Table 1 Descriptive statistics of the variables used

\begin{tabular}{llccrr}
\hline Variables & Obs & Mean & Std. Errors & \multicolumn{1}{c}{ Min } & Max \\
\hline EDS & 658 & 22.570 & 17.998 & 1.550 & 85.271 \\
SDS & 658 & 33.814 & 17.715 & 3.125 & 80.702 \\
GDS & 658 & 48.779 & 8.353 & 33.929 & 71.429 \\
ROE & 658 & 6.726 & 17.999 & -198.100 & 73.650 \\
MBR & 658 & 1.204 & 0.569 & 0.426 & 5.473 \\
Stock Return & 658 & 0.112 & 0.761 & -1.000 & 14.034 \\
Leverage & 658 & 0.437 & 0.193 & 0.049 & 0.981 \\
Log (Asset size) & 658 & 28.564 & 1.485 & 23.492 & 32.731 \\
\hline
\end{tabular}

The variables are $E D S$ environmental disclosure score, $S D S$ social disclosure score, GDS governance disclosure score, $R O E$ return on equity, MBR market-to-book ratio implying Tobin's q, Stock Return annual stock market return, Leverage leverage ratio as proxy for risk, Log (Asset size) log value of asset size Data source: Bloomberg 
Table 2 Linear correlations of the variables used. The sample period runs from 2008 to 2014

\begin{tabular}{lllllllll}
\hline & EDS & SDS & GDS & ROE & MBR & Stock Return & Leverage & Asset size \\
\hline EDS & 1 & & & & & & \\
SDS & 0.8445 & 1 & & & & & \\
GDS & 0.8321 & 0.8435 & 1 & & & & \\
ROE & 0.0307 & 0.0655 & 0.0858 & 1 & & & \\
MBR & 0.1610 & 0.2114 & 0.1642 & 0.1461 & 1 & & \\
Stock Return & 0.0164 & 0.0226 & 0.004 & 0.1556 & 0.0565 & 1 & \\
Leverage & 0.1232 & 0.1075 & 0.163 & -0.2868 & -0.1164 & -0.0353 & 1 & \\
Asset size & 0.6339 & 0.5651 & 0.6334 & 0.0364 & -0.147 & -0.0847 & 0.3182 & 1 \\
\hline
\end{tabular}

The variables are EDS environmental disclosure score, $S D S$ social disclosure score, GDS governance disclosure score, $R O E$ return on equity, MBR market-to-book ratio implying Tobin q, Stock Return annual stock market return, Leverage leverage ratio as proxy for risk, Log (Asset size) log value of asset size

Data source: Bloomberg

variables such as the leverage ratio and asset size after taking log function show moderate volatility.

The correlations in Table 2 imply that the variables used are not highly correlated with each other. The highest correlations are observed among the ESG scores, while these high correlations among them do not lead to multicollinearity issues. Our VIF test result indicates that there is no problem of collinearity. The correlations among the financial performance (FP) measures are quite moderate. Furthermore, the correlation between the three ESG scores and FP measure is observed to be the highest for the MBR. In addition, some leverage is observed, implying that the firms' risk indicator is negatively related with all three FP measures. Meanwhile, the asset size shows a mixed correlation with the FP measures.

Table 3 provides more detailed descriptive statistics of the three ESG scores' mean values over the study period. We observe that there is a general upward trend in the three ESG score during the period of $2008 \sim 2014$. This upward trend is slightly intercepted in 2011 for SDS and in 2012 for both EDS and GDS as a small decrease is observed in these two scores. However, the upward trend is immediately restored and then becomes faster, except for GDS. Most of all, the fact that all three ESG scores show constant increases over the study period indicates that the CSR commitment in the Korean listed firms is quite resilient and noticeable, considering that there was no sharp drop in these ESG scores during the financial crisis of $2008 \sim 2010$. Another

Table 3 EDS, SDS and GDS. The sample period runs from 2008 to 2014

\begin{tabular}{llll}
\hline Year & EDS & SDS & GDS \\
\hline 2008 & 16.402 & 29.827 & 48.024 \\
2009 & 18.810 & 30.360 & 48.290 \\
2010 & 20.790 & 32.921 & 49.601 \\
2011 & 22.578 & 32.644 & 49.696 \\
2012 & 21.630 & 30.590 & 48.670 \\
2013 & 29.134 & 40.525 & 48.784 \\
2014 & 28.647 & 39.834 & 48.385 \\
Average & 22.570 & 33.814 & 48.779 \\
\hline
\end{tabular}

Data source: Bloomberg 
observation is that both EDS and SDS exhibit a relatively high variance (as shown in the standard errors) among the KOSPI firms, while this does not hold for GDS. This observation suggests that the firms listed in Korea may have different levels of environmental and social responsibility. Nonetheless, all of the firms show very similar levels of governance responsibility.

\section{Regression model}

This section describes the empirical method used to examine the effect of ESG on FP. Our panel regression model is as follows:

$$
y_{i t}=\beta_{0}+\beta_{1} \mathrm{EDS}_{\mathrm{it}}+\beta_{2} \mathrm{SDS}_{\mathrm{it}}+\beta_{3} \mathrm{GDS}_{\mathrm{it}}+\beta_{4} \mathrm{x}_{\mathrm{it}}^{\prime}+\epsilon_{\mathrm{it}}, \text { for } \mathrm{i}=1,2, \ldots, \mathrm{k} \text { and } \mathrm{t}=1,2, \ldots, \mathrm{n}
$$

where $y_{i t}$ is the corporate financial performance (FP) measure (i.e. ROE, MBR and Stock Returns) for firm i at time n. $\mathrm{EDS}_{\mathrm{it}}, \mathrm{SDS}_{\mathrm{it}}$ and $\mathrm{GDS}_{\mathrm{it}}$ represent the firm's social responsibility score in the three dimensions, i.e. environmental, social and governance responsibility efforts, respectively. $x_{i t}^{\prime}$ is a vector composed of control variables such as the leverage ratio and log asset size, lagged dependent variables $\left(\mathrm{y}_{\mathrm{it}-1}\right)$, and cross-terms among ESG scores $\left.\left(\mathrm{EDS}_{\mathrm{it}} \times \mathrm{SDS}_{\mathrm{it}}, \mathrm{GDS}_{\mathrm{it}} \times \mathrm{SDS}_{\mathrm{it}}, \mathrm{EDS}_{\mathrm{it}} \times \mathrm{GDS}_{\mathrm{it}}\right)\right)^{2}$ The choice of control variables could be justified by recent CSR studies and other finance literature testing FP. The $\epsilon_{\text {it }}$ term contains both an independent idiosyncratic error term $u_{i t}$ and unobserved firm specific characteristics $c_{i t}$, such that $\epsilon_{i t}=u_{i t}+c_{i t}$. Depending on the assumption on the unobserved firm specific characteristics term, $c_{i t}$, we can run two different panel regressions. Firstly, we run a random effect panel under the assumption that $c_{i t}$ varies across time. Secondly, assuming that $\mathrm{c}_{\mathrm{it}}$ does not change across time, we run a fixed effect panel. We also run simple pooled OLS (Ordinary Least Square) regression, as done by Nollet, Filis, and Mitrokostas (2016). In this case, we need to consider the specific time period effect additionally, because the pooled OLS does not distinguish the firms' identity and time trend on its own, unlike the above two panel models. Thus, we introduce $D_{t}$ as a dummy variable to capture the effect of the financial crisis during the period of $2008 \sim 2010\left(D_{t}\right.$ takes a value of one for the years $2008 \sim 2010$ and zero otherwise). For the pooled OLS, our regression model is modified as follows:

$$
\mathrm{y}_{\mathrm{it}}=\beta_{0}+\beta_{1} E D S_{i t}+\beta_{2} S D S_{i t}+\beta_{3} G D S_{i t}+\beta_{4} x_{i t}^{\prime}+D_{t}+\epsilon_{i t}
$$

In addition, we run a quasi-maximum likelihood estimate to avoid the critique that including a lagged dependent variable in the random effect panel might violate the independency between the unobserved firm specific characteristics $c_{i t}$ and dependent variables. ${ }^{3}$ Finally, we examine the quadratic relationship between the ESG scores and FP, as in Nollet, Filis, and Mitrokostas (2016), in order to consider the possibility of a U shaped or inversed $\mathrm{U}$ shaped relationship. This is about testing Hypothesis 2. Now the equation becomes:

$$
\mathrm{y}_{\mathrm{it}}=\beta_{0}+\beta_{1} E D S_{i t}+\beta_{2} S D S_{i t}+\beta_{3} G D S_{i t}+\beta_{4} E D S_{i t}^{2}+\beta_{5} S D S_{i t}^{2}+\beta_{6} G D S_{i t}^{2}+\beta_{7} x_{i t}^{\prime}+\epsilon_{i t}
$$

\section{Empirical findings}

Table 4 reports the linear regression results for the effect of the three ESG scores on FP (financial performance). The relationship between the ESG score and ROE is 


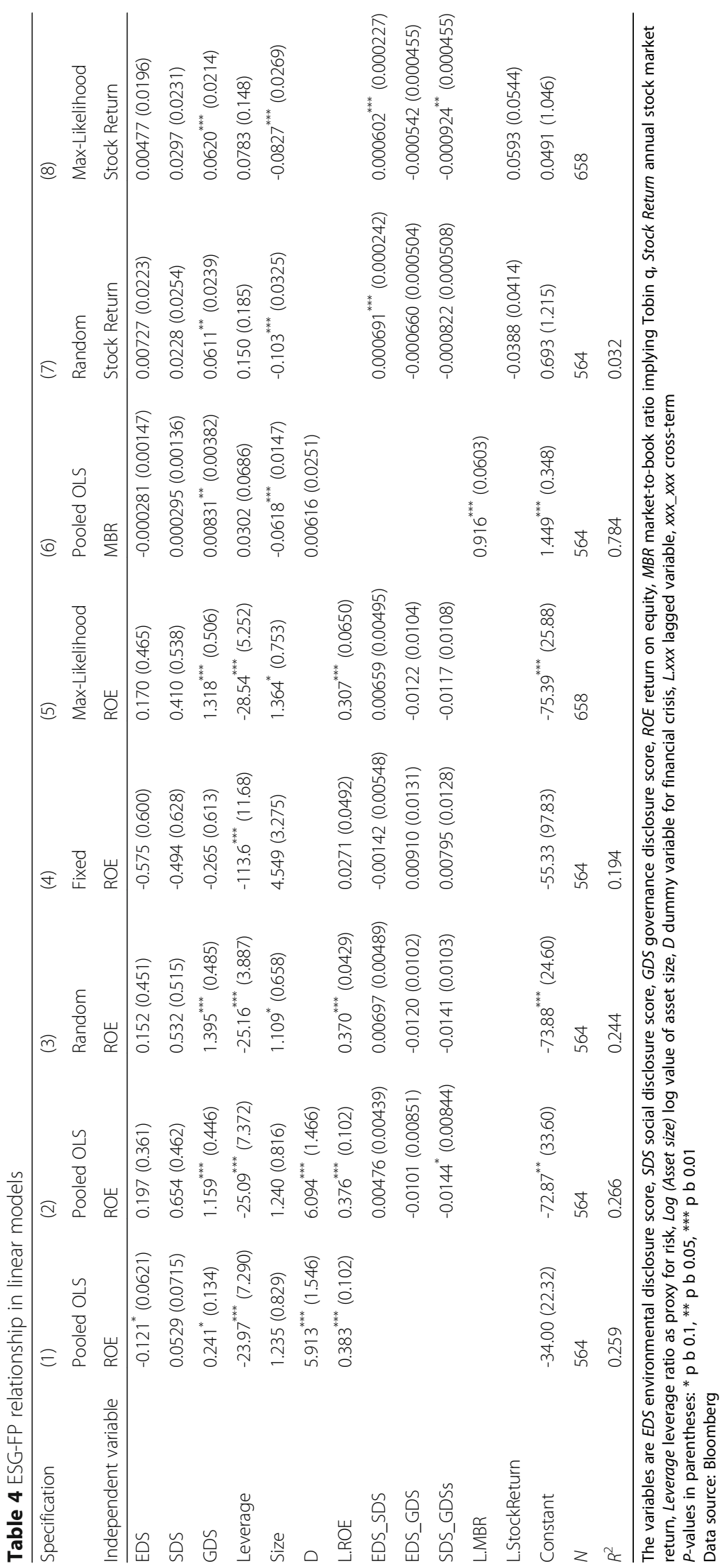


reported in specifications (1)-(5), viz. the two types of pooled OLS, random effect panel, fixed effect panel and quasi-maximum likelihood regression, respectively. The regression results suggest that, in the linear specifications, the effect of ESG on ROE is mixed and insignificant for EDS and SDS. On the other hand, the effect of GDS is shown to be positive with significance in specifications (2), (3) and (5). By the way, the ESG cross-terms' coefficients show mixed signs with no statistical significance. Therefore, we can confirm that Hypothesis 1 holds only for GDS. This result is in line with Margolis et al. (2009)'s empirical result of the positive effect of CSR on accounting based profits. Also, the insignificance of the ESG cross-terms' coefficients is the same as that reported by Nollet, Filis, and Mitrokostas (2016).

We also applied the same five types of regression methods to MBR and, then, the Stock Return as dependent variables. However, we can only find three cases with any level of significance in any of the ESG coefficients. Thus, we report only specifications (6)-(8). Here, we can see that the effect of GDS on both MBR and Stock Return is significant, whereas neither EDS nor SDS has any significant effect on these two FP measures. ${ }^{4}$ In the latter cases, we can also observe significance in the cross-term of $\mathrm{EDS}_{\text {it }} \times \mathrm{SDS}_{\mathrm{it}}$. However, with there being no significant effect of ESD and SDS at all, it is difficult to find any meaningful implications. Finally, the lagged dependent variables are significantly positive for ROE and MBR, but not for Stock Return.

Now we turn our attention to the quadratic models of equation (3) with the same types of regression methods. In this case, we ignored the ESG cross-term for simplicity, considering both their insignificance in the linear regression and increased number of dependent variables (three additional ESG cross-term variables) in the quadratic model. This quadratic model finds some interesting results: there exist both $U$ shaped and inversely U shaped relationships between the ESG scores and FP in Korea stock market. This is in sharp contrast to the finding of only a $U$ shaped relationship by Nollet, Filis, and Mitrokostas (2016) in the US stock market.

Table 5 provides the quadratic regression results. The quadratic relationship of the ESG disclosure scores with ROE is reported in specifications (1)-(4) for the pooled OLS, random effect panel, fixed effect panel and quasi-maximum likelihood regression, respectively. Firstly, we detected a U shaped relationship between the EDS and ROE in specification (3). This supports Hypothesis 2. By the way, the U shaped relationship in Table 5 is also related to the negative coefficient of EDS in the previous linear specification (1) in Table 4, although the significance level is weak (i.e. 10\%). Combining these two findings on the coefficients of the EDS terms in Tables 4 and 5 explains well that, while a negative relation between EDS and ROE may occur at an early stage of EDS in Table 4 (i.e. linear framework), Table 5 (i.e. quadratic framework) picks up a positively turning point in the latter part of a convexly $U$ shaped relationship. We would like to emphasize that our finding fills the gap between the negative relationship reported by both Mittal et al. (2008) and Fisher-Vanden and Thorburn (2011) and the U shaped relationship stressed by Brammer and Millington (2008), and Nollet and al (2016). ${ }^{5}$ Furthermore, although Nollet, Filis, and Mitrokostas (2016) failed to find a U shaped relation in US EDS (i.e. corporate environmental effort), our study on Korean listed firms found a $U$ shaped relation in EDS. The $U$ shaped relation between EDS and ROE (accounting-based FP measures) suggests that although investment in environmental activities may not pay off immediately, it pays off ultimately after a certain threshold 


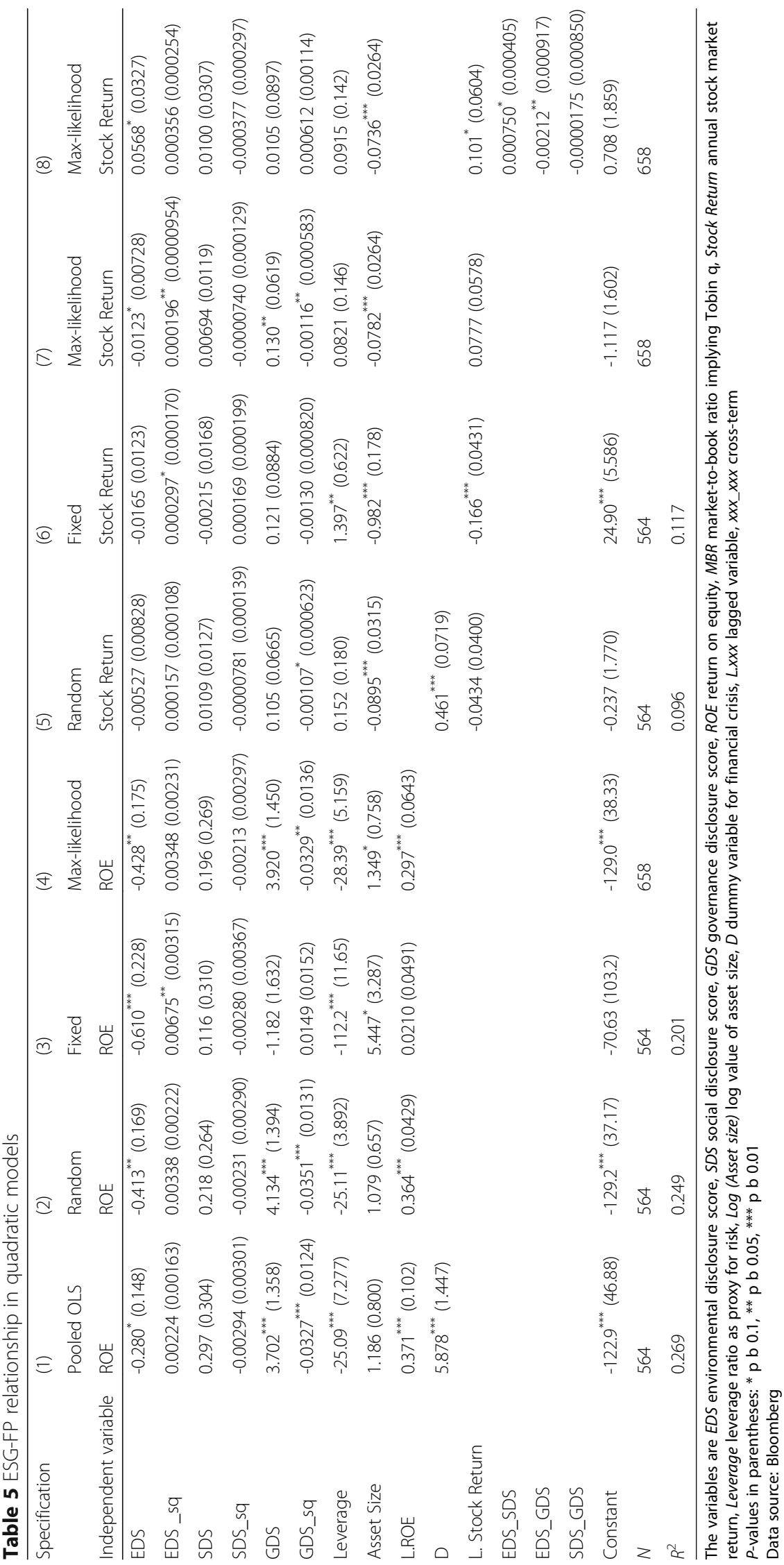


level of EDS is accumulated. Based on the coefficients of the EDS $\mathrm{it}_{\mathrm{it}}$ and $\mathrm{EDS}_{\mathrm{it}}^{2}$ terms in specification (3) of Table 5, we can compute the threshold level of the EDS score. It is calculated to be 45.2 , which is far greater than the current average EDS value of 28.6 (as of 2014). This suggests that improving environmental responsibility is a costly procedure and that it may take a long time to reap the fruits. Until then, Korean firms need to continue their EDS efforts.

Secondly, our quadratic test results identify an inverse $U$ curve relationship of the governance responsibility activities in the Korean firms. The results are in sharp contrast to the finding of only a U shaped relation in US GDS in the study of Nollet, Filis, and Mitrokostas (2016). However, in reality, such an inversely $U$ shaped relation is understandable. This is a very general phenomena known as the law of diminishing marginal returns in micro-economics. When the input variable has a positive effect on the output variable, the extent of the contribution from the former to the latter starts to diminish as the input amount accumulates. In the same way, when GDS increases, the marginal extent of its contribution to the corporate financial performance starts to diminish at a certain point. An interesting question is when the firm's financial performance stops increasing as GDS increases. We can compute the stopping point based on the estimate of the coefficient from specifications (1) (2) and (4) of Table 5. It is calculated to be in the range of $56.6 \sim 59.5$, which is far greater than the 2014 average GDS value of 48.6. This suggests that improving governance responsibility is still helpful to improve the ROE, at least for Korean firms.

We also ran the same quadratic regression procedures on MBR and Stock Return. However, we found a few cases of significant ESG coefficients only with Stock Return. Interestingly, we could not find any significant quadratic coefficients with MBR. Thus, we only report the Stock Return cases in specifications (5)-(8) in Table 5. Among them, in specification (7), we observed an inversely $U$ shaped effect of GDS with moderate significance, whereas none of the other regressions showed any significant quadratic relationships. Finally, when it comes to the control variables, risk and asset size retain similar levels of significance to the linear model. Overall, the signs of the control variables and coefficients remain unchanged, regardless of the specification.

\section{Conclusion}

In the present study, we investigated the relationship between corporate social responsibility and financial performance using the Bloomberg ESG disclosure score. Particularly, we considered the three individual ESG scores, namely EDS, SDS and GDS. The FP (Financial Performance) was measured using accounting-based measures, i.e. ROE, a market-based measure, i.e. Stock Returns, and proxy of Tobin's q, i.e. MBR. The control variables include the debt-to-equity ratio, asset size and lagged dependent variables. For the sample, all of the firms listed on the KOSPI market, whose ESG scores are available from 2008 to 2014, were used.

Overall, the results from the linear model suggested that a significantly positive relationship exists between GDS and ROE. Further analysis with quadratic terms provided evidence of an inversely $U$ shaped relationship between GDS and the accounting-based FPs. Also, the quadratic test provided evidence of a U shaped relationship between EDS 
and the accounting-based FP, which implies that CSR activity pays off only after a certain threshold amount of CSR has been accumulated. In other words, before this point is reached, the required additional CSR expenditures may act to decrease FP at early stage. The most prominent finding is the following. Through Tables 4 and 5, we found evidence that ESG effort made in Korean firms will ultimately be beneficial. Specifically, though EDS effort in Korea as of now shows negative profit for its initial cost, it will ultimately make a profit in the long-run with further commitment. Meanwhile, improving governance responsibility (i.e. GDS effort) is still fruitful in improving the firm's profit. Our study also indicated the need to use a broader measure of CSR to obtain a clearer relationship between corporate social responsibility and financial performance.

As regards the management implications, our results can provide firms with useful guidelines when considering their CSR investments. As our study suggests that there is no immediate detrimental impact or disadvantage from CSR activities, firms have enough rationale to utilize their resources to improve their CSR and to enhance the expectations of their stakeholders. Overall, companies with effective CSR strategies can increase the willingness of their stakeholders to invest in them.

The main limitation of this study is the fact that the ESG score fails to take into account the actual CSR actions a firm engages in. In other words, a firm's ESG disclosure activity index might differ from the type of CSR (or ESG here) effort they actually made. This drawback is commonly shared with other measurements of corporate social responsibility, as noted in the works of Nollet, Filis, and Mitrokostas (2016) and Baron (2001). The second limitation is derived from the limited number of samples. Out of the 700 KOSPI listed firms, we were able to use the data from only 94 firms whose ESG scores are available in Bloomberg. However, more significant results could have been driven if the sample size was enlarged. The final limitation in our research is the possibility that other variables could affect the associations among the CSR and financial performance. For instance, factors affecting the business environment (e.g., uncertainty (Arag'on-Correa and Sharma 2003)) or degree of competition (Bagnoli and Watts 2003) might influence the relationship. These issues will be the subject of future research.

\section{Endnotes}

${ }^{1}$ The governance score, in particular, considers CSR oriented issues such as "internally developed statements of mission or values, codes of conduct, and principles relevant to economic, environmental, and social performance and the status of their implementation", "externally developed economic, environmental, and social charters, principles, or other initiatives to which the organization subscribes or endorses" and "key topics and concerns that have been raised through stakeholder engagement, and how the organization has responded to those key topics and concerns, including through its reporting" (Bloomberg, 201, p74-75).

${ }^{2}$ Because size and risk have been suggested in previous articles to be factors that affect both the firm's performance and CSP (e.g., Ullman, 1985), each of these characteristics was operationalized as a control variable. Size is relevant because there is some evidence that smaller firms may not exhibit as many overt socially responsible behaviors as do larger firms. Perhaps this is the case because, as they mature and grow, firms attract more attention from external constituents and need to respond more openly to stakeholder demands (c.f., Burke, Logsdon, Mitchell, Reiner, and Vogel, 1986). The management's risk 
tolerance influences its attitude toward activities that have the potential to 1) elicit savings (e.g., a recycling or waste reduction effort, costly at first but potentially money saving in the long run, such as 3 M Corporation's Pollution Prevention Pays program; 2) incur future or present costs (e.g., pollution control equipment that helps avoid future fines), or 3) build (environmentally friendly firm) or destroy (perceived as unfriendly to certain types of people) markets. As a proxy for management's risk tolerance, we use the firm's debt ratio.

${ }^{3}$ The maximum likelihood used in our study was pioneered by Bhargava and Sargan in their study (1983), which incorporates all of the restrictions implied by the model in an optimally efficient way. Their method has recently been implemented by Kripfganz (2015) in a Stata command called xtdpdqml, which stands for "cross-section time-series dynamic panel data estimation by quasi-maximum likelihood."

${ }^{4}$ These results are available upon request.

${ }^{5} \mathrm{Mittal}$ et al. (2008) and Fisher-Vanden and Thorburn (2011) attributed the negative effect of CSR on FP to either the early massive cost of CSP affecting the aggregate corporation's financial performance or the negative market reaction to news of the company joining the environmental friendly program. Meanwhile, Brammer and Millington (2008) provided some support for the existence of a U shaped relationship between CSP and CFP on the firm-level relationship. Furthermore, Nollet, Filis, and Mitrokostas (2016) found an empirically $U$ shaped relationship between the firm's governance effort and its ROA (Return of Asset) with US S\&P500 listed firms.

\section{Acknowledgement}

Authors appreciate Korea Institute of Finance for allowing the first author to use Bloomberg DB when he was a visiting scholar.

Authors' contributions

All authors read and approved the final manuscript.

Competing interests

The authors declare that they have no competing interests.

\section{Author details}

${ }^{1}$ Department of Global Finance and Banking, Inha University, 100 Inha-Ro, Nam-Gu, Incheon 22212, Korea. ${ }^{2}$ College of Business Administration, Inha University, 100 Inha-Ro, Nam-Gu, Incheon 22212, Korea.

Received: 1 April 2016 Accepted: 2 November 2016

Published: 12 December 2016

\section{References}

Andrews KR (1973). Can best corporations be made moral. Harv Bus Rev 51(3):57-64

Arag'on-Correa JA, Sharma S (2003) A contingent resource-based view of proactive corporate environmental strategy. Acad Manag Rev 28(1):71-88

Aras G, Crowther D (2008) Governance and sustainability: an investigation into the relationship between corporate governance and corporate sustainability. Manag Decis 46(3):433-448

Aupperle KE, Carroll AB, Hatfield JD (1985) An empirical examination of the relationship between corporate social responsibility and profitability. Acad Manag J 28(2):446-463

Bagnoli M, Watts S (2003) Selling to socially responsible consumers: competition and the private provision of public goods. J Econ Manag Strateg 12(3):419-445

Barnett ML, Salomon RM (2006) Beyond dichotomy: the curvilinear relationship between social responsibility and financial performance. Strateg Manag J 27(11):1101-1122

Barnett ML, Salomon RM (2012) Does it pay to be really good? Addressing the shape of the relationship between social and financial performance. Strateg Manag J 33(11):1304-1320

Baron DP (2001) Private politics, corporate social responsibility, and integrated strategy. J Econ Manag Strateg 10(1):7-45

Baron D (2008) Managerial contracting and corporate social responsibility. J Public Econ 92(1-2):268-288

Bassen A, Kovacs AMM (2008) Environmental, social and governance key performance indicators from a capital market perspective. Zeitschrift für Wirtschafts-und Unternehmensethik 9(2):182-192

Beltratti A (2005) The complementarity between corporate governance and corporate social responsibility. Geneva Papers Risk Insurance-Issues Pract 30(3):373-386

Besley T, Ghatak M (2007) Retailing public goods: the economics of social responsibility. J Public Econ 91(9):1645-1663

Bénabou R, Tirole J (2010) Individual and corporate social responsibility. Economica 77(305):1-19 
Bowen HR (1953) Social Responsibility of the Business man. Harper and Row, New York

Brammer S, Millington, A (2008). Does it pay to be different? An analysis of the relationship between corporate social and financial performance. Strateg Manag J 29(12):1325-1343

Butz C, Pictet O (2008) The SRI performance paradox. Pictet, Geneva, https://www.pictet.com/content/dam/pictet documents/pdf_documents/pam_sri/sri_performance_paradoxen.pdf. Accessed 20 Feb 2016

Carroll AB (1979) A three dimensional conceptual model of corporate social performance. Acad Manag Rev 4(4):497-505

Chambers E, Moon J, Sullivan M, Matten D (2003) A seven country study of CSR website reporting. http://citeseerx.ist psu.edu/viewdoc/download?doi=10.1.1.470.5464\&rep=rep1\&type=pdf. Accessed 22 May 2016

Choi TH, Pae J (2011) Business ethics and financial reporting quality: evidence from Korea. J Bus Ethics 103(3):403-427

Crisóstomo VL, Freire F, de Souza X, Vasconcellos FC (2011) Corporate social responsibility, firm value and financial performance in Brazil. Soc Responsibility J 7(2):295-309

Davis K, Blomstrom RL (1975) Business and Society. McGraw-Hill, New York

Davis I, Stephenson E (2006). Ten trends to watch in 2006, vol 1. The McKinsey Quarterly, pp 1-5

Dobers P (2009) Corporate social responsibility: management and methods. Corp Soc Responsib Environ Manag 16(4):185-191

Donaldson T, Preston LE (1995) The stakeholder theory of the corporation: concepts, evidence, and implications. Acad Manag Rev 20(1):65-91

Drucker PF (1984) The new meaning of corporate social responsibility. Calif Manag Rev 26(2):53-63

Eells R, Walton C (1961) Conceptual Foundations of Business. Richard D. Irwin, Homewood, Illinois

Epstein EM (1987) The corporate social policy process: beyond business ethics, corporate social responsibility, and corporate social responsiveness. Calif Manag Rev 29(3):99-114

Fisher-Vanden K, Thorburn KS (2011) Voluntary corporate environmental initiatives and shareholder wealth. J Environ Econ Manag 62(3):430-445

Friedman M (1970) The social responsibility of business is to increase its profits. New York Times Magazine, 122-124

García-Gallego A, Georgantzís N (2009) Market effects of changes in consumers' social responsibility. J Econ Manag Strateg 18(1):235-262

Jamali D, Safieddine AM, Rabbath M (2008) Corporate governance and corporate social responsibility synergies and interrelationships. Corp Gov 16(5):443-459

Kim Y, Kim S-Y (2010) The influence of cultural values on perceptions of corporate social responsibility: Application of Hofstede's dimensions to Korean public relations practitioners. J Bus Ethics 91(4):485-500

Levitt T (1958) The dangers of social responsibility. Harv Bus Rev 36(5):41-50

Manasakis C, Mitrokostas E, Petrakis E (2013) Certification of corporate social responsibility activities in oligopolistic markets. Can J Econ 46(1):282-309

Manasakis C, Mitrokostas E, Petrakis E (2014) Strategic corporate social responsibility activities and corporate governance in imperfectly competitive markets. Manag Decis Econ 35(7):460-473

Margolis JD, Elfenbein HA, Walsh, JP (2007) Does it pay to be good? A meta-analysis and redirection of research on the relationship between corporate social and financial performance. Ann Arbor 1001:48109-1234

Margolis JD, Elfenbein HA, Walsh JP (2009) Does it Pay to Be Good... And Does it Matter? A Meta-Analysis of the Relationship between Corporate Social and Financial Performance (March 1). Available at SSRN: https://ssrn.com/abstract=1866371 or http://dx.doi.org/10.2139/ssrn.1866371

McGuire JW (1963) Business and Society. McGraw-Hill, New York

McWilliams A, Siegel D (2000) Corporate social responsibility and financial performance: Correlation or misspecification? Strateg Manag J 21(5):603-609

McWilliams A, Siegel DS (2011) Creating and capturing value: strategic corporate social responsibility, resource-based theory, and sustainable competitive advantage. J Manag 37(5):1480-1495

McWilliams A, Siegel DS, Wright PM (2006) Introduction: corporate social responsibility: strategic implications. J Manag Stud 26(1):1-18

Mittal RK, Sinha N, Singh A (2008) An analysis of linkage between economic value added and corporate social responsibility. Manag Decis 46(9):1437-1443

Nejati M, Ghasemi S (2012) Corporate social responsibility in Iran from the perspective of employees. Soc Responsibility J 8(4):578-588

Nollet J, Filis G, Mitrokostas E (2016) Corporate social responsibility and financial performance: a non-linear and disaggregated approach. Econ Model 52(B):400-407

Oh WY, Chang YK, Martynov A (2011) The effect of ownership structure on corporate social responsibility: empirical evidence from Korea. J Bus Ethics 104(2):283-297

Orlitzky M, Schmidt FL, Rynes SL (2003) Corporate social and financial performance: A metaanalysis. Organization Stud, 24(3):403-441

Park H, Blenkinsopp J, Oktem MK, Omurgonulsen U (2008) Cultural orientation and attitudes toward different forms of whistleblowing: a comparison of south Korea, turkey, and the U.K. J Bus Ethics 82(4):929-939

Peiris D, Evans J (2010) The relationship between environmental social governance factors and US stock performance. J Investing 19(3):104-112

Porter ME, Kramer MR (2006) The link between competitive advantage and corporate social responsibility. Harv Bus Rev 84(12):78-92

Russo MV, Fouts PA (1997) A resource-based perspective on corporate environmental performance and profitability. Acad Manag J 40(3):534-559

Schreck P (2011) Reviewing the business case for corporate social responsibility: New evidence and analysis. J Bus Ethics 103(2):167-188 Waddock SA, Graves SB (1997) The corporate social performance-financial performance link. Strateg Manag J 18(4):303-319 Wu ML (2006) Corporate Social Performance, Corporate Financial Performance and Firm Size: A Meta-Analysis. J Am Acad Bus 8(1):163-171 